\title{
Long-term variations in primary production in a eutrophic sub-estuary. I. Seasonal and spatial patterns
}

\author{
Charles L. Gallegos* \\ Smithsonian Environmental Research Center, PO Box 28, Edgewater, Maryland 21037, USA
}

\begin{abstract}
Daily rates of phytoplankton primary production were calculated from measurements of light saturation curves of photosynthesis for $20 \mathrm{yr}$ at 6 stations on the Rhode River, Maryland (USA). Daily production, corrected for the geometry and spectrum of the underwater light field, averaged 1319 (range 1.4 to 15800 ) $\mathrm{mg} \mathrm{C} \mathrm{m}^{-2} \mathrm{~d}^{-1}$. Log-transformation of the exact solution for depthintegrated daily production permitted linear analysis of seasonal and spatial patterns in production and the factors that determine it. The seasonal signal was the greatest source of variation, followed by spatial then interannual. The seasonal pattern was driven by coinciding summer maxima in both the chlorophyll a ( $\mathrm{chl}$ a) biomass, $B$, and the light saturated photosynthetic rate normalized to $\mathrm{chl} a, P_{\max }^{B}$. The spatial pattern was characterized by a region in which production was relatively constant despite declining depth, a station at which production was reduced by truncation of the depth profile of production, and an area where mean production was lowest but variance was highest, due to local flow causing either localized blooms or washout of biomass and high turbidity at the station furthest up the estuary. Analysis of the components contributing to the variance in production indicated that variance in $B$ and $P_{\max }^{B}$ added nearly equally to it. Covariance between $B$ and the light attenuation coefficient reduced the variance in production. The analytical approach adopted here allowed these patterns to be discerned against a high degree of overall variability, and should be similarly useful in a wide range of systems.
\end{abstract}

KEY WORDS: Phytoplankton - Primary production · Daily production · Estuary · Seasonal variability $\cdot$ Spatial variability $\cdot$ Rhode River

\section{INTRODUCTION}

Nearly half of the human population lives within $150 \mathrm{~km}$ of the coast (UN Atlas of the Oceans 2013), thus understanding processes occurring at the landwater interface is of great importance for the long term sustainability of coastal ecosystems. Primary productivity by phytoplankton is an important process that supplies fixed carbon to higher trophic levels, drives the biogeochemical cycling of carbon, and is an indicator of eutrophication due to excess anthropogenic nutrient loading (Nixon 1995).
The factors that affect phytoplankton production are well understood in broad terms to be light availability, phytoplankton biomass, and environmental influences such as temperature and nutrients that affect the efficiency of conversion of absorbed light into fixed carbon (Platt \& Sathyendranath 1988). Nutrients influence production directly as a requisite component of phytoplankton biomass, sometimes triggering blooms (Loftus et al. 1972, Spatharis et al. 2007), and indirectly by influencing phytoplankton photosynthetic physiology (Geider et al. 1998). Physiological adaptation to nutrient history is an impor- 
tant consideration in biogeochemical modeling of ocean carbon cycles (Marañón et al. 2003, Armstrong 2006), even though ambient nutrient concentrations tend to be poor predictors of photophysiological properties in field studies (Harrison \& Platt 1980, Bouman et al. 2005).

Proximity to land affects the factors controlling phytoplankton production in a number of ways that may be difficult to isolate. For example, elevated stream flow due to a large storm may deliver large amounts of nutrients, sediment, and organic matter that may alternatively stimulate local blooms, elevate turbidity, or wash biomass out of the system (Peierls et al. 2012). Freshwater discharge also influences the physical environment in which primary production occurs by promoting vertical density stratification (Malone et al. 1988) and establishing a longitudinal salinity gradient which affects the distribution of species (Quinlan \& Phlips 2007).

Geomorphic factors related to the nearshore environment can affect the spatial distribution of phytoplankton production in ways that may be highly site specific. For example, shoaling of the depth may prevent complete development of the vertical photosynthesis profile (Oviatt et al. 2002, Brush \& Brawley 2009). Wind generated waves may resuspend bottom sediments, resulting in higher light attenuation in shallow waters (Lawson et al. 2007), and also suspend benthic microalgae which may contribute to production as a form of pseudo-phytoplankton (MacIntyre et al. 1996). Such factors are further influenced by site-specific geomorphic factors such as fetch that modulate wave energy (Arfi et al. 1993).

Because of this wide array of factors affecting phytoplankton production, it is clear that developing an understanding of production in coastal systems requires a large observational base and an analytical procedure capable of separating diverse influences (Yoshiyama \& Sharp 2006). Developing an improved understanding of the temporal and spatial scales of variability in phytoplankton primary production in coastal systems is important because of the variety of processes that depend on it, e.g. oxygen balance, $\mathrm{CO}_{2}$ uptake, nutrient assimilation, supply of fixed carbon to higher trophic levels, and others (Cloern \& Jassby 2010). A means of partitioning the variance in production among causal components is needed to provide ecological understanding of how primary production is structured by environmental and biological factors within a given system and to provide a basis for comparison amongst different systems. Such an analysis has practical utility for identifying the factors that may need management and setting of appropriate targets, whether to reverse eutrophication (Nixon 2009) or to optimize sustainable fisheries yields (e.g. Ware \& Thomson 2005).

The objectives of this work were to understand how the main factors that determine primary production vary seasonally and along a spatial gradient of influence by local versus remote processes. A 20 -yr time series of primary production (as daily rates measured at weekly to biweekly intervals) in the Rhode River (Maryland, USA) sub-estuary of the Chesapeake Bay was analyzed for seasonal and spatial patterns. The procedure for calculation of daily rates of production from photosynthesis-irradiance $(P-E)$ curves was reviewed. It was shown that logtransformation of the canonical expression for daily production (e.g. Platt \& Sathyendranath 1993) results in a sum that quantifies the relative contributions of chlorophyll, light attenuation, and photophysiological parameters to the percent variability in primary production. The procedure was applied to measurements in the Rhode River to partition the variation in daily production and causal factors amongst seasonal, spatial, and interannual components. Results indicated several modes by which local flow and bathymetry associated with containment in a subestuary embayment cause divergence of primary production from conditions in the main stem estuary.

\section{MATERIALS AND METHODS}

\section{Study site}

The Rhode River (Fig. 1, 38 $52^{\prime} \mathrm{N}, 76^{\circ} 31^{\prime} \mathrm{W}$ ) is a shallow, eutrophic tributary on the western shore in the mesohaline zone of the Chesapeake Bay in Maryland (USA). Water depth averages $2 \mathrm{~m}$ and ranges from $4 \mathrm{~m}$ at the mouth to $1 \mathrm{~m}$ in a broad area of subtidal mudflats at a divergence just down estuary of the station designated 5.2 (Fig. 1). The principal freshwater source to the Rhode River is Muddy Creek, an intermittent stream draining a 2378 ha watershed that is mostly forested $(57 \%)$, with lesser amounts of grassland $(24 \%)$, wetland $(8.5 \%)$, and cropland $(6.9 \%)$. Surface salinity at a central station (station 3.8 km, Fig. 1) averages 9.6 (SD 2.3, range 2.3 to 17$)$. The head-to-mouth salinity gradient becomes negligible in the summer due to subsidence of flow by Muddy Creek (Jordan et al. 1991a). Stoichiometric analyses (Jordan et al. 1991a) and nutrient addition bioassays (Gallegos \& Jordan 1997) indicate that phytoplankton are consistently $\mathrm{N}$ limited in summer and occasionally P limited in winter-spring. Nitrate 


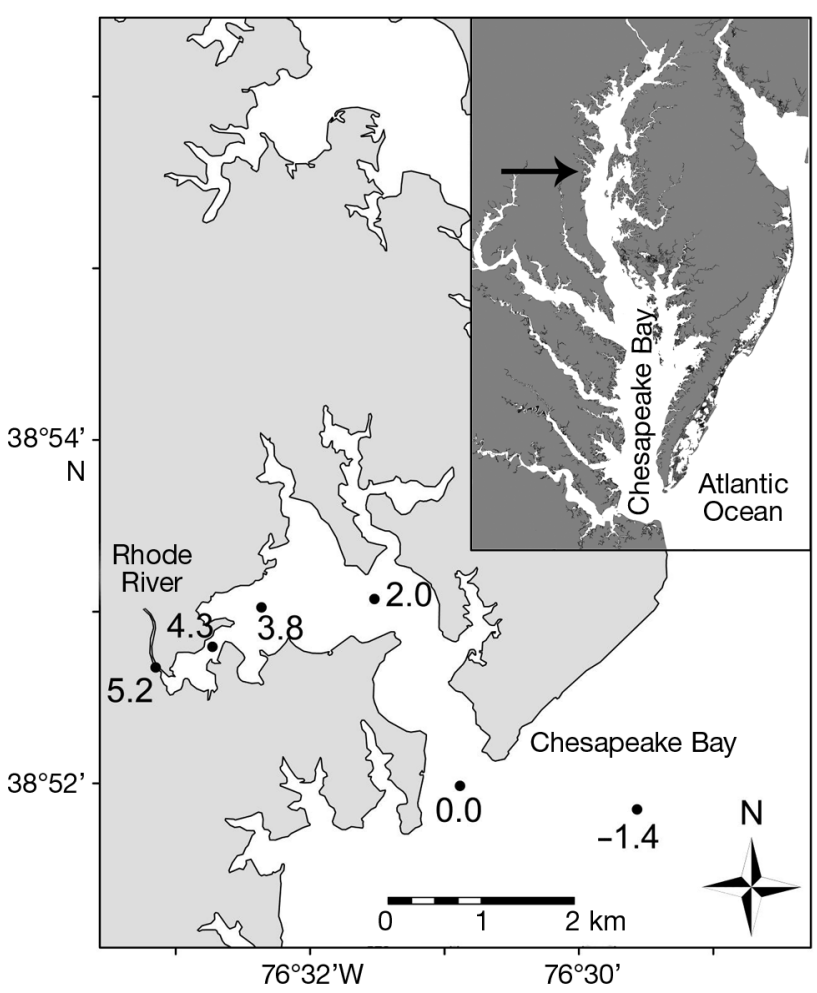

Fig. 1. Rhode River, Maryland (USA), showing location of sampling stations, designated by their distance from the mouth $(\mathrm{km})$. Inset with arrow locates the Rhode River on the western shore of Chesapeake Bay

input at the mouth of the sub-estuary by flow from the Susquehanna River, the main freshwater source to the upper Chesapeake Bay (long term discharge data available from US Geological Survey - http:// waterdata.usgs.gov/nwis/uv?site_no=01578310), exceeds that locally by Muddy Creek (Jordan et al. 1991a). Despite strong N limitation in summer, there is generally a consistent background concentration of ca. $4 \mu \mathrm{mol} \mathrm{NH}_{4}^{-}$due to benthic and water column regeneration processes (Jordan et al. 1991a). Additional details about the system have been described previously (Jordan et al. 1991a,b).

\section{Field measurements}

Measurements made on cruises of the Rhode River were described in detail by Gallegos (2012a). Briefly, 6 stations were sampled at weekly to bi-weekly intervals from 1990 to 2009. The sampling period usually ranged from early March through mid-December depending on ice and weather conditions or availability of boats, though in some years sampling continued all year, especially early in the series. Due to funding lim- itations, measurements were commenced late in 2007. The need to perform photosynthesis measurements (see below) on samples precluded sampling at a fixed tidal stage. Stations were designated by their distance from the mouth $(\mathrm{km}$, positive up estuary, Fig. 1). Measurements made at each station (except Stn 5.2) have been described previously (Gallegos 2012a). Samples for depth-averaged chlorophyll concentration used to characterize the water column biomass (parameter $B$ in Eq. 6 and subsequent equations; see section 'Calculation of primary production') were collected by slowly lowering and raising a Labline ${ }^{\mathrm{TM}}$ Teflon ${ }^{\mathrm{TM}}$ sampler in less time than required to fill it. Samples for photosynthesis vs. irradiance $(P-E)$ parameters and discrete chlorophyll $a(\mathrm{chl} a)$ concentration were collected by filling the sampler at the Secchi depth. Stn 5.2 was accessed from land and was sampled from a fish sampling weir that spans the tidal creek at a divergence (Fig. 1). In situ measurements at Stn 5.2 were limited to temperature, salinity by refractometer, and Secchi depth. The diffuse attenuation coefficient for downwelling irradiance (photosynthetically active radiation, $\mathrm{PAR}, 400-700 \mathrm{~nm}$ ), $K_{\mathrm{d}}$, (Table 1 ) at Stn 5.2 was determined as $\Gamma / Z_{\mathrm{SD}}$, where $Z_{\mathrm{SD}}=$ Secchi depth, and the coefficient $\Gamma$ was determined from the annual average of the product $Z_{\mathrm{SD}} \times K_{\mathrm{d}}$ determined at the nearest station sampled by boat (Stn 4.3 ) at which vertical PAR profiles were measured. The $Z_{\mathrm{SD}} \times K_{\mathrm{d}}$ product as annual means for Stn 4.3 ranged from 0.66 to 1.60 and trended generally downward with time (see e.g. Gallegos et al. 2011). This model reproduced $K_{\mathrm{d}}$ at $\operatorname{Stn} 4.3$ with a root-mean-square error of $0.91 \mathrm{~m}^{-1}$ which is $16 \%$ smaller than that estimated using a fixed value for $Z_{\mathrm{SD}} \times K_{\mathrm{d}}$, and compared with an overall average $K_{\mathrm{d}}$ of $2.21 \mathrm{~m}^{-1}$.

\section{Photosynthesis measurements}

Phytoplankton photosynthesis was measured as ${ }^{14} \mathrm{C}$ uptake in 1-h incubations using the small volume 'photosynthetron' method of Lewis \& Smith (1983) as described by Gallegos (2012a). Light was supplied by a Westinghouse $400 \mathrm{~W}$ metal halide lamp. These lamps have a wide but irregular spectrum (Bubenheim et al. 1988). A site-specific empirical factor to correct calculations of primary production for spectral selectivity of light absorption by phytoplankton was derived based on radiative transfer simulations (using Hydrolight, Mobley 1994) of the underwater spectrum of scalar irradiance. Details are reported in the Supplement at www.int-res.com/articles/suppl/ m502p053_supp.pdf. The procedure resulted in a 
Table 1. Definitions of symbols and units of terms used

\begin{tabular}{|c|c|c|}
\hline Symbol & Definition & Units \\
\hline$A$ & Scale factor in expression for daily production, $A=B P_{\max }^{B} D / K_{\mathrm{d}}$ & $\mathrm{mgC} \mathrm{m} \mathrm{C}^{-1}$ \\
\hline$B$ & Phytoplankton pigment biomass as chl a & $\mathrm{mg} \mathrm{m}^{-3}$ \\
\hline$b_{0}$ & Coefficient in General Linear Model (GLM) for factor Month & dimensionless \\
\hline$b_{1}$ & Coefficient in GLM for factor Station & dimensionless \\
\hline$b_{2}$ & Coefficient in GLM for factor Year & dimensionless \\
\hline$b_{3}$ & Coefficient in GLM for interaction Month $\times$ Station & dimensionless \\
\hline$D$ & Photoperiod & $\mathrm{h}$ \\
\hline$E$ & Photosynthetically active radiation, (PAR) & mol photons $\mathrm{m}^{-2} \mathrm{~s}^{-1}$ \\
\hline$E_{0}$ & Incident downwelling irradiance & mol photons $\mathrm{m}^{-2} \mathrm{~s}^{-1}$ \\
\hline$E_{0}{ }^{\mathrm{m}}$ & Maximal noontime incident irradiance & mol photons $\mathrm{m}^{-2} \mathrm{~s}^{-1}$ \\
\hline$E_{\mathrm{d}}$ & Downwelling irradiance at depth & mol photons $\mathrm{m}^{-2} \mathrm{~s}^{-1}$ \\
\hline$E_{\mathrm{k}}$ & Photoadaptation parameter, $P_{\max }^{B} / \alpha^{B}$ & mol photons $\mathrm{m}^{-2} \mathrm{~s}^{-1}$ \\
\hline$E_{*}^{\mathrm{m}}$ & Maximal incident irradiance normalized to photoadaptation parameter, $E_{0}^{\mathrm{m}} / E_{\mathrm{k}}$ & dimensionless \\
\hline$F_{0, H}$ & Integral of non-dimensional photosynthesis profile from the surface to bottom & dimensionless \\
\hline$F_{0, \infty}$ & Integral of non-dimensional photosynthesis profile from surface to infinite depth & dimensionless \\
\hline$F_{H, \infty}$ & Integral of non-dimensional photosynthesis profile from bottom $(H)$ to infinite depth & dimensionless \\
\hline$H$ & Depth of the water column, surface to bottom irradiance & $\mathrm{m}$ \\
\hline$K_{\mathrm{d}}$ & Diffuse attenuation coefficient for downwelling & $\mathrm{m}^{-1}$ \\
\hline$P$ & Daily areal production from the surface to bottom & $\mathrm{mg} \mathrm{C} \mathrm{m} \mathrm{m}^{-2} \mathrm{~d}^{-1}$ \\
\hline$P^{B}$ & Phytoplankton photosynthesis normalized to chlorophyll concentration & $\mathrm{mg} \mathrm{C} \mathrm{mg}^{-1} \mathrm{chl} \mathrm{a} \mathrm{h}^{-1}$ \\
\hline$P_{\max }^{B}$ & Maximum phytoplankton photosynthesis normalized to pigment biomass, $B$ & $\mathrm{mg} \mathrm{C} \mathrm{mg}^{-1} \mathrm{chl} \mathrm{a \textrm {h } ^ { - 1 }}$ \\
\hline$R_{B}$ & $Y$-intercept of photosynthesis-irradiance curve & $\mathrm{mg} \mathrm{C} \mathrm{mg}^{-1} \mathrm{chl} \mathrm{a} \mathrm{h}^{-1}$ \\
\hline$S$ & Spectral correction factor, function of optical depth & dimensionless \\
\hline$t$ & Time of day & $\mathrm{h}$ \\
\hline$z$ & Geometric depth below the surface & $\mathrm{m}$ \\
\hline$Z_{\mathrm{OD}}$ & Optical depth for photosynthetically active radiation & dimensionless \\
\hline$\alpha^{B}$ & Initial slope of the phytoplankton photosynthesis-irradiance curve at low light & $\begin{array}{l}{\left[\mathrm{mg} \mathrm{C} \mathrm{mg}^{-1} \mathrm{chl} \mathrm{a} \mathrm{h}^{-1}\right]} \\
{\left[\mathrm{mol} \text { photon } \mathrm{m}^{-2} \mathrm{~s}^{-1}\right]^{-1}}\end{array}$ \\
\hline$\gamma$ & Exponent in Case 1 expression for diffuse attenuation coefficient, $K_{\mathrm{d}} \approx \chi B^{\gamma}$ & dimensionless \\
\hline$\chi$ & Coefficient in Case 1 expression for diffuse attenuation coefficient, $K_{\mathrm{d}} \approx \chi B^{\gamma}$ & dimensionless \\
\hline
\end{tabular}

correction factor, $S\left(Z_{\mathrm{OD}}\right)$, that averaged 0.78 and was a function of the optical depth, $Z_{\mathrm{OD}}\left(=K_{\mathrm{d}} \times\right.$ depth), given by:

$$
S\left(Z_{\mathrm{OD}}\right)=\frac{1}{1+\left(0.0647 Z_{\mathrm{OD}}-0.0307\right)}
$$

Light intensities (PAR) in the photosynthetron were routinely measured at the termination of the incubations using a Licor LI-185B quantum radiometer and $2 \pi$ sensor inside a specially made adaptor that reproduced the geometry of the hole in the aluminum block and held the sensor at the level of the sample meniscus. One-time comparison with measurements made using a $19 \mathrm{~mm}$ diameter, $4 \pi$ Biospherical Instruments QSL-2200 probe inside the scintillation vials indicated that the routine procedure underestimated light intensities by a factor of 1.77 (slope of Type II regression, $\mathrm{R}^{2}=0.95, \mathrm{n}=39$ ). Failure to make this adjustment would lead to errors in calculated daily production ranging from negligible (optically shallow, light-saturated water column) to biased high by a factor up to 1.77 at low incident light (depth profile light limited, see Eq. 7).

\section{Calculation of primary production}

The rate of photosynthesis normalized to pigment biomass, $P^{B}$, as a function of available light, $E$, was represented by a hyperbolic tangent function (Jassby \& Platt 1976):

$$
P^{B}(E)=P_{\max }^{B} \tanh \left(\frac{\alpha^{B} E}{P_{\max }^{B}}\right)+R^{B}
$$

where $P_{\max }^{B}=$ the maximal rate of ${ }^{14} \mathrm{C}$ uptake at light saturation (see Table 1 for definition of terms), $\alpha^{B}=$ the slope of the linear portion of the curve at low light intensities, and $R^{B}=$ the zero-light intercept, retained to prevent bias in the fitting of $\alpha^{B}$. For in-depth discussion of the physiological interpretation of the $P-E$ parameters see Geider \& MacIntyre (2002). Parameters were estimated by minimizing the sum of squared residuals between model predictions and observations using the Solver ${ }^{\mathrm{TM}}$ routine in Excel $^{\mathrm{TM}}$. Estimates of $\alpha^{B}$ were divided by the 1.77 factor to account for the underestimation of light intensity by the routine measurement procedure. The fitted parameters, along with depth-averaged chl a concentra- 
tions and diffuse attenuation coefficients are available online (Gallegos 2012b).

The depth-integrated daily rate of primary production was calculated according to the formalism of Platt \& Sathyendranath (1993, their Eq. 39), which should be consulted for full derivation of the equation. Briefly, the daily input of incident irradiance, $E_{0}(t)$, is represented as a half-sine:

$$
\begin{aligned}
E_{0}(t) & =E_{0}^{\mathrm{m}} \sin \left(\frac{\pi t}{D}\right) \quad 0<t \leq D \\
& =0 \quad D<t \leq 24
\end{aligned}
$$

where $t=$ time of day relative to sunrise, $E_{0}^{\mathrm{m}}=$ maximal noon incident irradiance, and $D=$ photoperiod; the time-varying downwelling irradiance at depth $z$, $E_{\mathrm{d}}(z, t)$, is given by:

$$
E_{\mathrm{d}}(z, t)=E_{0}(t) \exp \left(-K_{\mathrm{d}} z\right)
$$

Photosynthesis is represented by an alternate function because it is integrable in an exponential light field:

$$
P^{B}(E)=P_{\max }^{B}\left[1-\exp \left(\frac{-\alpha^{B} E}{P_{\max }^{B}}\right)\right]
$$

The functional form representing $P^{B}(E)$ has a minor effect on the daily integral (Behrenfeld \& Falkowski 1997), and a small correction for using Eq. (2) to estimate the $P_{\max }^{B}$ and $\alpha^{B}$ parameters, and Eq. (5) for daily integration is derived below. Substitution of Eqs. (3) \& (4) into (5) gives photosynthesis as a function of depth and time (Platt et al. 1990), which is integrated over the water column depth, $H$, and time to give daily production, $P_{H, T}$ :

$$
\begin{aligned}
& P_{H, T}= \\
& B P_{\max }^{B} \int_{t=0}^{D} \int_{z=0}^{H}\left\{1-\exp \left[-\left(\alpha^{B} E_{0}^{\mathrm{m}} \sin (\pi t / D) \mathrm{e}^{-K_{\mathrm{d}} z}\right) / P_{\max }^{B}\right]\right\} \mathrm{d} z \mathrm{~d} t
\end{aligned}
$$

where photosynthetic parameters and pigment biomass, $B$, are assumed uniform with depth. The double integral has an exact solution in terms of a scale factor, $A=B P_{\max }^{B} D / K_{\mathrm{d}}$, and a function $F$ of the dimensionless irradiance, $E_{*}^{\mathrm{m}}=E_{0}^{\mathrm{m}} / E_{\mathrm{k}}$, where $E_{\mathrm{k}}=$ $P_{\max }^{B} / \alpha^{B}$ is the photoadaptation parameter separating light-limiting from light-saturating irradiances. Substitution into Eq. (6) and integration leads to:

$$
P_{H, T}=A \times F_{0, H}\left(E_{*}^{\mathrm{m}}\right)
$$

The function $F$ (approximately linear at low $E_{*}^{\mathrm{m}}$ ) is given by a fifth-order polynomial expansion of $E_{*}^{\mathrm{m}}$ with coefficients given by Platt \& Sathyendranath (1993). Casting the equation in terms of a dimensionless irradiance assures that the solution is valid across all trophic states and optical water types. For an optically shallow water column, the function $F$ is evaluated by first performing the depth integration in Eq. (7) from the surface to $z=\infty$, then subtracting the evaluation of $F$ from $z=H$ to $\infty$ (Platt \& Sathyendranath 1993), that is:

$$
F_{0, H}\left(E_{*}^{\mathrm{m}}\right)=F_{0, \infty}\left(E_{*}^{\mathrm{m}}\right)-F_{H, \infty}\left(E_{*}^{\mathrm{m}} \mathrm{e}^{-K_{\mathrm{d}} H}\right)
$$

Note that, with identical parameters, Eq. (2) saturates at a lower light intensity compared with Eq. (5). Therefore, $E_{\mathrm{k}}$ used to define $E_{*}^{\mathrm{m}}$ must be reduced for Eq. (6) to produce the same daily production rate as numerical integration of Eq. (2) in an exponential light field. This factor was determined to be 0.759 . The need for this adjustment could be avoided by fitting Eq. (5) directly to the $P^{B}$ and $E$ data, but for this study, individual $P^{B}$ and $E$ data were no longer digitally available.

Hourly averages of incident solar irradiance were recorded at the Smithsonian pier on the Rhode River using a Licor LI-185B quantum sensor and Licor logger. Data were corrected for $6 \% \mathrm{yr}^{-1}$ drift between factory calibrations in 1990, 1997, and 2004. $E_{0}{ }^{\mathrm{m}}$ was calculated from the daily integral of incident quantum flux assuming a half-sine variation over the day. On days when there were no measurements of incident irradiance, $E_{0}{ }^{\mathrm{m}}$ was calculated by the model of Gregg \& Carder (1990). Calculated rates of daily primary production and the components of Eq. (7) are available online (Gallegos 2013).

\section{Data analysis}

Eq. (7), with its spectral correction factor, was logtransformed to give a linear model enabling analysis and ranking of the factors governing the relative magnitude and variances of $P_{H, T}$ by standard formulae for the mean and variance of the sums of random variables, that is:

$$
\ln \left(P_{H, T}\right)=\ln (A)+\ln \left[F_{0, H}\left(E_{*}^{\mathrm{m}}\right)\right]+\ln \left[S\left(Z_{\mathrm{OD}}\right)\right]
$$

and

$$
\begin{aligned}
\operatorname{var}\left[\ln \left(P_{H, T}\right)\right]= & \operatorname{var}[\ln (A)]+\operatorname{var}\left[\ln \left(F_{0, H}\right)\right] \\
& +\operatorname{var}\left[\ln \left(S\left(Z_{\mathrm{OD}}\right)\right)\right] \\
& +2 \operatorname{cov}\left[\ln (A), \ln \left(F_{0, H}\right)\right] \\
& +2 \operatorname{cov}\left[\ln (A), \ln \left(S\left(Z_{\mathrm{OD}}\right)\right)\right] \\
& +2 \operatorname{cov}\left[\ln \left(F_{0, H}\right), \ln \left(S\left(Z_{\mathrm{OD}}\right)\right)\right]
\end{aligned}
$$


It was anticipated that $\ln (A)$ would be the dominant contributor to $\operatorname{var}\left[\ln \left(P_{H, T}\right)\right]$ (Behrenfeld \& Falkowski 1997); therefore, $\ln (A)$ was further analyzed in terms of its components:

$$
\ln (A)=\ln (B)+\ln \left(P_{\max }^{B}\right)+\ln (D)-\ln \left(K_{\mathrm{d}}\right)
$$

and

$$
\begin{aligned}
& \operatorname{var}[\ln (A)]=\operatorname{var}[\ln (B)]+\operatorname{var}\left[\ln \left(P_{\max }^{B}\right)\right] \\
&+\operatorname{var}[\ln (D)]+\operatorname{var}\left[\ln \left(K_{\mathrm{d}}\right)\right] \\
&+2 \operatorname{cov}\left[\ln (B), \ln \left(P_{\max }^{B}\right)\right] \\
&+2 \operatorname{cov}[\ln (B), \ln (D)] \\
&+2 \operatorname{cov}\left[\ln \left(P_{\max }^{B}\right), \ln (D)\right] \\
&-2 \operatorname{cov}\left[\ln \left(K_{\mathrm{d}}\right), \ln (B)\right] \\
&-2 \operatorname{cov}\left[\ln \left(K_{\mathrm{d}}\right), \ln \left(P_{\max }^{B}\right)\right] \\
&-2 \operatorname{cov}\left[\ln \left(K_{\mathrm{d}}\right), \ln (D)\right]
\end{aligned}
$$

All variance and statistical analyses were performed on natural log-transformed variables, so the ln designations will be omitted for notational convenience in presentation of results.

The components on the right hand sides of Eqs. (9a) \& (10a) were analyzed for spatial, seasonal, and interannual patterns using the General Linear Model (GLM) procedure in the DataDesk 6.1 software, which estimated coefficient vectors in the general relationship:

$$
\begin{aligned}
y= & \text { Constant }+b_{0}(\text { Month })+b_{1}(\text { Station })+ \\
& b_{2}(\text { Year })+b_{3}(\text { Month } \times \text { Station })+\text { error }
\end{aligned}
$$

where $y$ is the response variable; $b_{j}$ are the coefficient vectors; Station, Month, and Year were treated as categorical variables; and error is the residual not explained by the categories or interactions, and consists of measurement uncertainties and 'event-scale' variability, broadly construed. Coefficients $b_{0}$ and $b_{1}$ quantify the main seasonal and spatial effects, respectively, while the (Month $\times$ Station) interaction term allows for local modification of the main seasonal pattern at different stations. Interannual patterns quantified by the coefficients of Year $\left(b_{2}\right.$ and additional interactions) are analyzed elsewhere (Gallegos 2014, this volume). Because Eqs. (9a) \& (10a) are linear and exact, the GLM coefficients for the terms on the right hand sides sum to those on the left hand sides. That is, the GLM analysis decomposes the seasonal and spatial variability in $\ln \left(P_{H, T}\right)$ (Eq. 9a) and $\ln (A)$ (Eq. 10a) into sums of their components. The vector of expected values for any of the variables is given by the sum of Constant + the coefficient vector for that variable. When converting GLM estimates of $\ln \left(P_{H, T}\right)$ back into an arithmetic scale, a bias correction was made as $\exp \left[\ln \left(\hat{P}_{H, T}\right)+s^{2} / 2\right]$, where $\left(\hat{P}_{H, T}\right)$ is the GLM prediction for $\ln \left(P_{H, T}\right)$ and $s^{2}$ is the variance of the residuals (Hayes \& Shonkwiler 2006). Alternatively, the back-transformed results could be presented as maximum-likelihood estimates of the geometric means (Limpert et al. 2001), i.e. without applying the $s^{2} / 2$ correction, with no qualitative changes in conclusions.

\section{RESULTS}

\section{Primary production}

Spectrally corrected daily production by phytoplankton in the Rhode River averaged $1319 \mathrm{mg} \mathrm{C} \mathrm{m}^{-2}$ $\mathrm{d}^{-1}(\mathrm{SD}=1180, \mathrm{n}=3443$, Fig. 2) and varied over 4 orders of magnitude from 1.4 to $15800 \mathrm{mg} \mathrm{C} \mathrm{m}^{-2}$ $\mathrm{d}^{-1}$. In most years, both the highest and lowest rates occurred at the most upstream station, $5.2 \mathrm{~km}$ (Fig. 2, crosses). The density of the data and high degree of variability in Fig. 2 accentuate the challenge of discerning temporal and spatial patterns in the data. Although there is much scatter in the data, a distinct winter minimum is apparent as a ' $\mathrm{V}$ ' shaped region without observations centered at the start of each year. Broad patterns of seasonal, spatial, and interannual variability can be seen in box-and-whisker plots

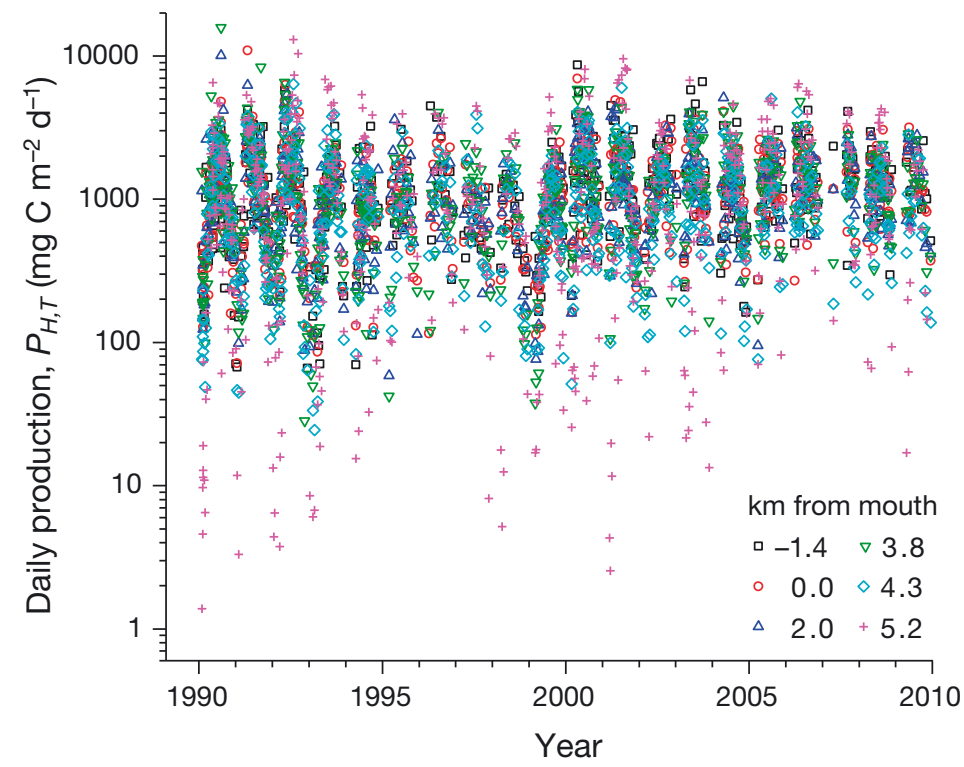

Fig. 2. Daily production by phytoplankton at 6 stations on the Rhode River as a function of time, 1990-2009. Station symbols are given in the figure 
of the untransformed data (Fig. 3). The seasonal pattern was evident as a winter minimum and broad summer maximum in all parameters of the distributions (Fig. 3A). The spatial variation was most evident as an upstream decline in the 1st percentile of the distribution (Fig. 3C). There was no obvious long term monotonic trend over the series (Fig. 3C), but interannual variations will be considered in detail elsewhere. Quantification of the roles of biomass, photophysiological parameters, and light attenuation in generating these patterns requires analysis in terms of Eqs.( 9a) \& (10a).

\section{Seasonal patterns}

GLM analysis of log-transformed $P_{H, T}$ identified month as the largest source of variance (MS $=126.3$ ), followed by station $(\mathrm{MS}=51.9)$ then year $(\mathrm{MS}=7.6)$,

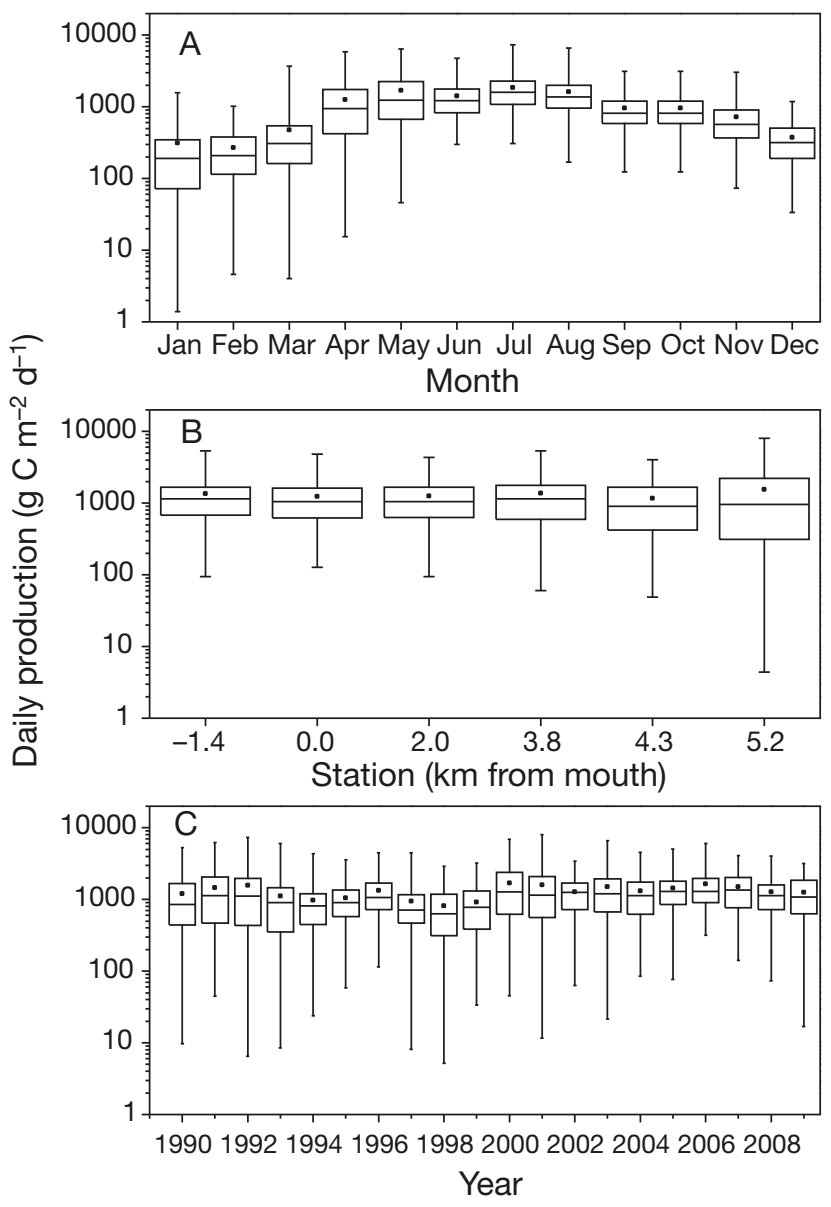

Fig. 3. Box-and-whisker plots of the distribution of daily production measurements in the Rhode River by (A) month, (B) station ( $x$-axis categorical, not to scale), and (C) year. Square $=$ mean $;$ horizontal bar $=$ median $;$ box limits $=25$ th to 75 th percentile; whisker $=1$ st to 99 th percentile all of which were statistically significant $\left(\mathrm{p}<10^{-4}\right)$. The seasonal expected values for $P_{H, T}$ in the Rhode River, shown as the sum of the factors on the right hand side of Eq. (9a), were minimal in January and peaked in July (Fig. 4A), and the pattern was driven almost entirely by the seasonal pattern in $A$. A weak seasonal pattern in $F_{0, H}$ roughly paralleled that for $A$ (Fig. 4A). The spectral correction factor, $S\left(Z_{\mathrm{OD}}\right)$, made a slight negative adjustment to the log-transformed $P_{H, T}$ which was slightly larger in magnitude in summer than in winter (Fig. 4A). Overall, monthly geometric mean production ranged from approximately $110 \mathrm{mg} \mathrm{C} \mathrm{m}^{-2} \mathrm{~d}^{-1}$ in January to $1530 \mathrm{mg} \mathrm{C} \mathrm{m}^{-2} \mathrm{~d}^{-1}$ in July (Fig. 4A, squares, right-hand axis).

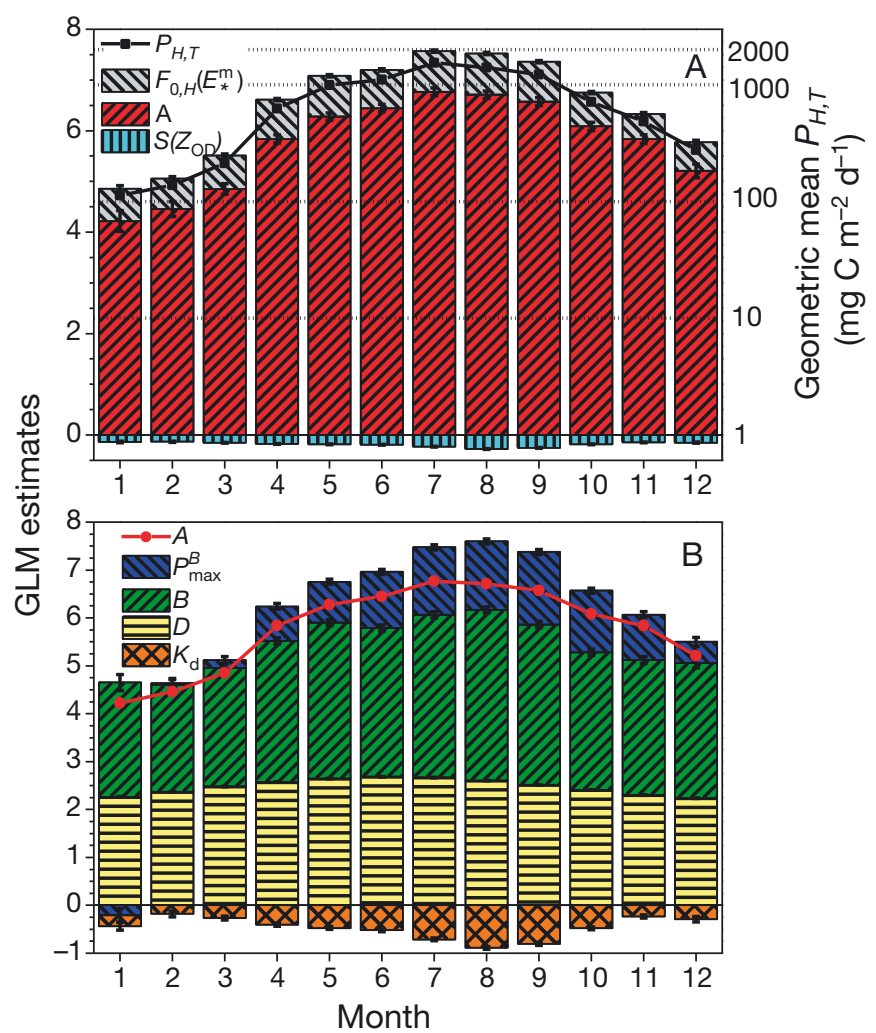

Fig. 4. (A) General Linear Model (GLM) estimates for the Month factor of natural log-transformed daily production, $\ln \left(P_{H, T}\right)$ (filled squares and line), and the terms that comprise it (bars): the scale factor, $\ln (A)$ (red); the dimensionless depth integral, $\ln \left[F_{0, H}\left(E_{*}^{\mathrm{m}}\right)\right]$ (gray); and the spectral correction factor, $\ln \left[S\left(Z_{\mathrm{OD}}\right)\right]$ (light cyan), plotted negative because it has values $<1$. Right hand axis shows the seasonal geometric mean $P_{H, T}$ in customary units, $\mathrm{mg} \mathrm{C} \mathrm{m}^{-2} \mathrm{~d}^{-1}$ and applies to squares only. (B) as in (A), for the scale factor, $\ln (A)$ (filled circles and line), and the factors that comprise it (bars): phytoplankton pigment biomass, $\ln (B)$ (green); phytoplankton light-saturated photosynthetic rate, $\ln \left(P_{\max }^{B}\right)$ (blue); diffuse attenuation coefficient, $\ln \left(K_{\mathrm{d}}\right)$ (orange); and photoperiod, $\ln (D)$ (yellow). The scale factor is given by $A=$ $B P_{\max }^{B} D / K_{\mathrm{d}}$, which becomes additive upon natural-log transformation. Error bars are $\pm 2 \mathrm{SE}$ 
The seasonal pattern in the primary controlling scalar, $A$, was determined by covarying patterns in the 3 main controls on its magnitude (Fig. 4B). In Fig. $4 \mathrm{~B}$, the negative of the estimate for $K_{\mathrm{d}}$ is plotted so that the coefficients for $B, P_{\text {max }}^{B} K_{\mathrm{d}}$ and $D$ sum to the monthly mean for $A$. The seasonal pattern in GLM estimates for $A$ can be seen to be driven by covarying winter minima and summer maxima in both $B$ and $P_{\max }^{B}$, which predominate over an opposing pattern in $K_{\mathrm{d}}$ (Fig. 4B). Subtle interactions cause $A$ (and also $P_{H, T}$ ) to peak in July. For example, the coefficients (seen as the height of individual bars) for $B$ peak in August while those for $P_{\max }^{B}$ peak in September (Fig. 4B). The June maximum in photoperiod combined with the peak $K_{\mathrm{d}}$ (a negative contribution) in August shifts the peak in $A$ from August to July. Effects of the occasional spring dinoflagellate blooms were evident in the small local maximum in May for $B$, but these blooms were relatively rare and, hence, have only a minor effect on the mean seasonality of $A$. The January minimum in $A$ was driven in part by the minimum in $P_{\text {max }}^{B}$ (Fig. $4 \mathrm{~B}$, monthly mean $P_{\max }^{B}$ $<1 \mathrm{mg} \mathrm{C} \mathrm{mg}^{-1} \mathrm{chl} \mathrm{a} \mathrm{h}^{-1}$ for January). The contribution by photoperiod, $D$, was smoothly varying, as expected, and constituted a large fraction of the overall magnitude of $A$ all year.

\section{Spatial patterns}

Spatial variations in $P_{H, T}$ were statistically insignificant from Stn -1.4 to 3.8 , while $P_{H, T}$ declined at the next 2 stations further up estuary (Fig. 5A). The coefficient on $A$ varied only weakly and erratically from Stn -1.4 to 4.3 ; thus, the decline in $P_{H, T}$ from Stn 3.8 to 4.3 was driven primarily by the minimum in $F_{0, H}$ at Stn 4.3. The further decline in $P_{H, T}$ from Stn 4.3 to 5.2 was caused by a decline in $A$ (Fig. 5A). GLM analysis (not shown) of terms on the right hand side of Eq. (8) indicated that the spatial pattern in $F_{0, H}\left(E_{*}^{\mathrm{m}}\right)$ was due almost entirely to the spatial pattern in $F_{H, \infty}\left(E_{*}^{\mathrm{m}} \mathrm{e}^{-K_{\mathrm{d}} H}\right)$, that is, due to truncation of the photic zone by the bathymetry. Another way to quantify the effect of the interaction of bathymetry and turbidity is the ratio $F_{0, H}\left(E_{*}^{\mathrm{m}}\right) / F_{0, \infty}\left(E_{*}^{\mathrm{m}}\right)$, representing the fraction of the infinite-depth water column included in the depth integral. The median of this ratio ranged from 0.98 at Stn -1.4 to 0.69 at Stn 4.3 , with a spatial pattern that paralleled the variation of $F_{0, H}\left(E_{*}^{\mathrm{m}}\right)$ in Fig. 5A.

The weak spatial pattern in $A$ from Stn -1.4 to 4.3 was the resultant of an up-estuary increasing trend in $B$ that was roughly counterbalanced by an increasing trend in $K_{\mathrm{d}}$ (plotted as its negative) up to Stn 4.3. An

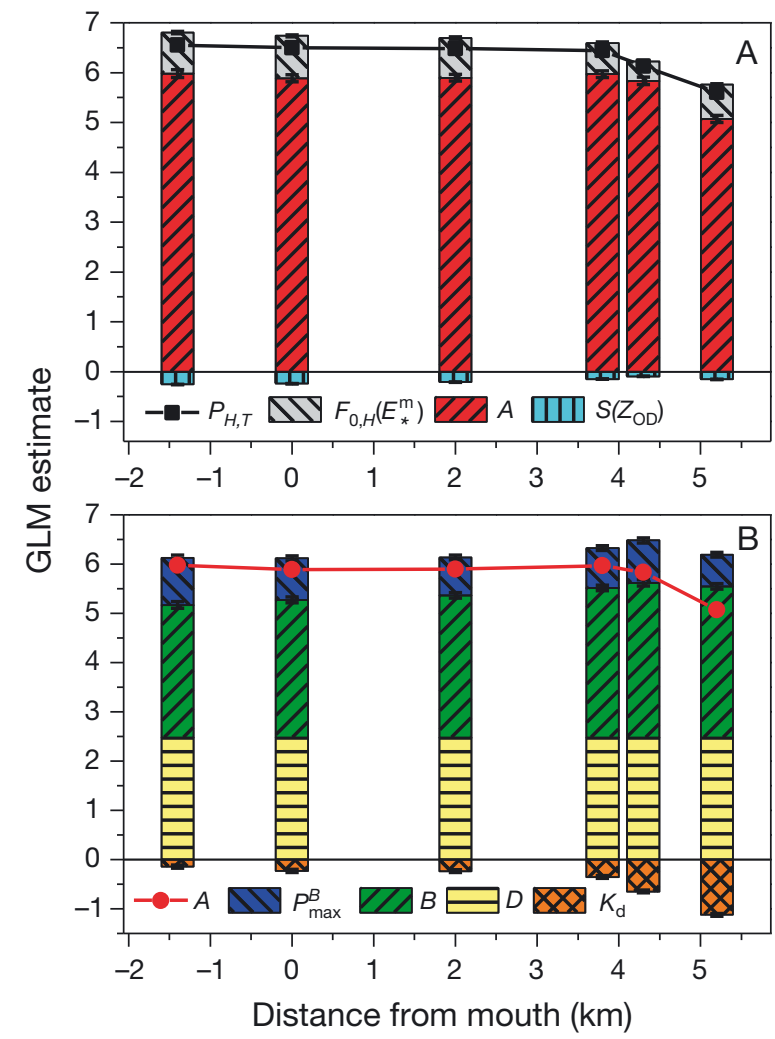

Fig. 5. (A) GLM estimates for the Station factor of natural log-transformed daily production, $\ln \left(P_{H, T}\right)$ (filled squares and line), and the terms that comprise it (bars): the scale factor, $\ln (A)$ (red); the dimensionless depth integral, $\ln \left[F_{0, H}\left(E_{*}^{\mathrm{m}}\right)\right]$ (gray); and the spectral correction factor, $\ln \left[S\left(Z_{\mathrm{OD}}\right)\right]$ (light cyan). (B) as in (A), for the scale factor, $\ln (A)$ (filled circles and line), and the factors that comprise it (bars): phytoplankton pigment biomass, $\ln (B)$ (green); phytoplankton light-saturated photosynthetic rate, $\ln \left(P_{\max }^{B}\right)$ (blue); diffuse attenuation coefficient, $\ln \left(K_{\mathrm{d}}\right)$ (orange); and photoperiod, $\ln (D)$ (yellow, constant with Station but included for proper scaling). Station is plotted as distance from mouth of the Rhode River $(\mathrm{km})$, positive up estuary. Error bars are $\pm 2 \mathrm{SE}$

even greater increase in $K_{\mathrm{d}}$ from Stn 4.3 to 5.2 then caused the sharp reduction in $A$ noted above (Fig. 5B). The spatial variability in $P_{\max }^{B}$ was relatively weak and non-systematic by comparison with the other variables and in comparison with its effect on the seasonal pattern (cf. Figs. 5B \& 4B).

Inclusion of the Month $\times$ Station interaction term in the GLM reveals the temporal pattern of the upestuary reductions in $P_{H, T}$ (Fig. 6). The seasonal pattern in the GLM coefficients (i.e. $b_{3}$ in Eq. 11) for the scalar, $A$, was very similar among the first 5 stations (Fig. 6A), while the coefficients for Stn 5.2 were sharply depressed in the spring (March through May) and fall (October through December). Plotting the GLM coefficients of the components that sum to 


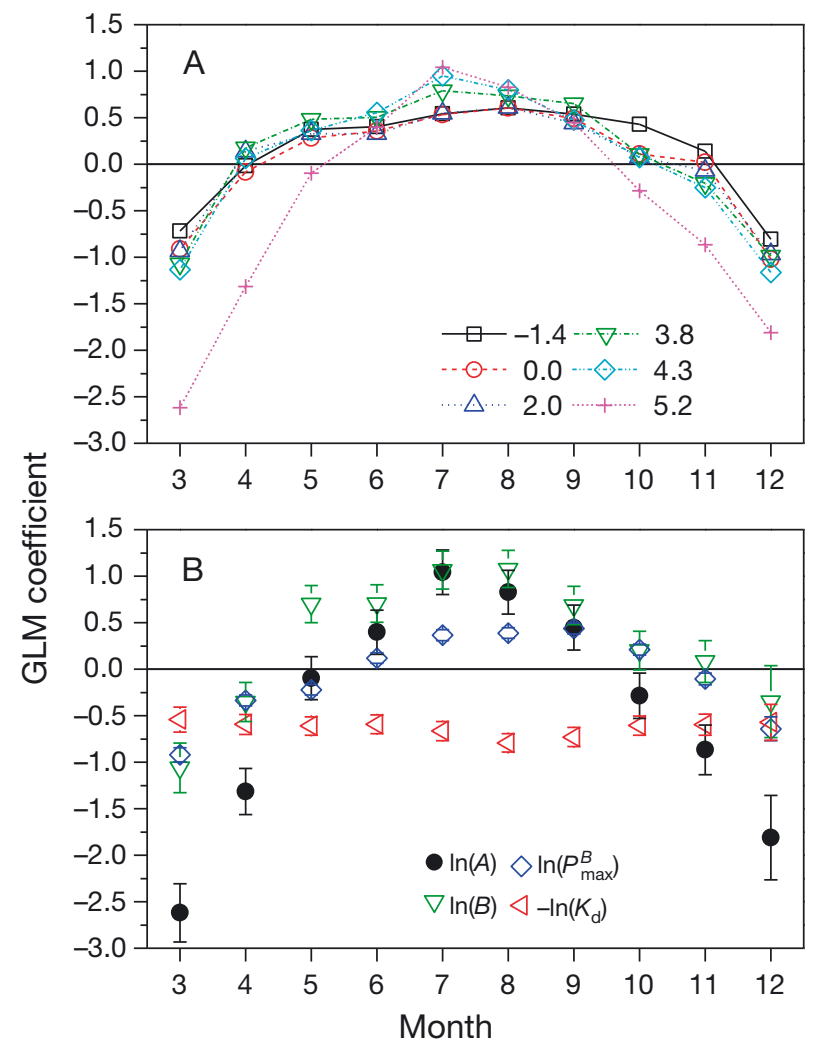

Fig. 6. (A) GLM coefficients for the Month $\times$ Station factor of the scalar term, $\ln (A)$ in Eq. (9a) \& (10a), plotted against month for 6 stations on the Rhode River. Station symbols are given in the figure. (B) as in (A) for the Month $\times$ Station factor of the scalar term and the components in Eq. (10a) that comprise it, for the uppermost station 5.2. Symbols are given in the figure. Error bars are $\pm 2 \mathrm{SE}$

$A$ at Stn 5.2 (Fig. 6B, omitting the photoperiod, $D$ ) indicates that the altered pattern at the uppermost station was due primarily to amplification of the seasonal excursion in the coefficients for $B$, which had values considerably lower than those of the monthly main effect in spring and fall. GLM coefficients for $K_{\mathrm{d}}$ at Stn 5.2 were uniformly lower and had reduced seasonal amplitude compared with the monthly main effect (cf. Figs. 6B \& 4B).

The overall effect of these interactions on the seasonal pattern at Stn 5.2 can be seen on an arithmetic scale as depression of productivity relative to other stations in spring (especially April to May) and elevation of productivity in summer months (July to August, Fig. 7). Some depression of $P_{H, T}$ in spring was also evident further down estuary at Stn 4.3, while some elevation of $P_{H, T}$ occurred in summer at Stns 4.3 and 3.8 (Fig. 7).

In the time series of $P_{H, T}$ (Fig. 2), it was noted that in most years the highest and lowest rates of production were observed at Stn 5.2. An example of the role of

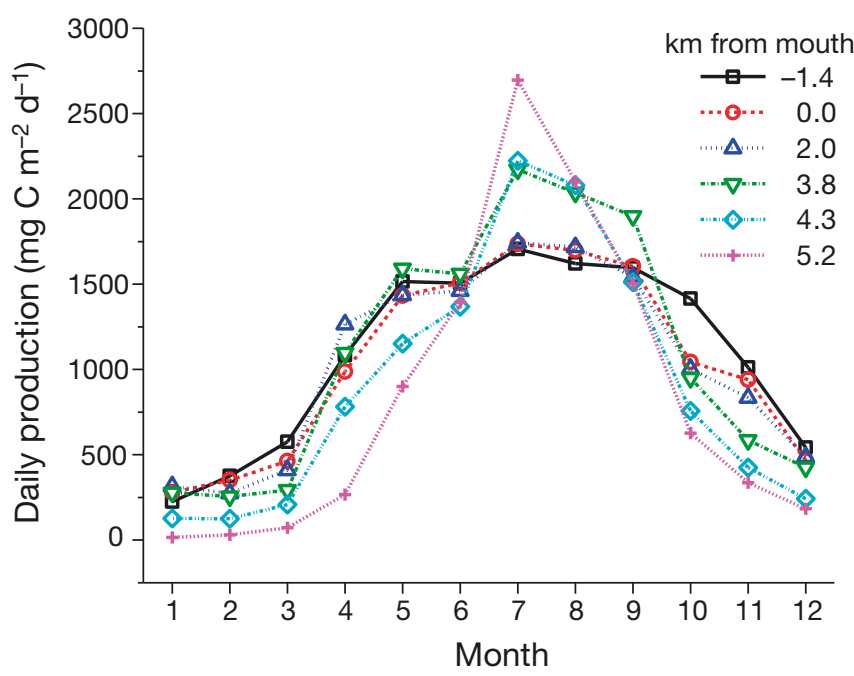

Fig. 7. Mean seasonal pattern in daily production at 6 stations in the Rhode River, estimated by GLM on natural logtransformed data with Month $\times$ Station interaction and back-transformed to an arithmetic scale. Symbols for stations are given in the figure

the local watershed in controlling primary production can be seen by comparing physical drivers of $B$ and $K_{\mathrm{d}}$ at Stns 4.3 and 5.2 in a selected year, 1994 (Fig. 8). That year, extremely high winter-spring flow of the Susquehanna River (third highest December through April flow during the observation period) suppressed spring dinoflagellate blooms through most of the estuary (see Fig. 1 in Gallegos et al. 1997). As salinity at Stn 5.2 began to rise seasonally (Fig. 8A), rainfall and local flows alternatively either supported large localized blooms far in excess of down-estuary levels (Fig. 8B, June), or in the case of a large rain event, resulted in washout of biomass (Fig. 8B, August) by driving salinity to 0 and causing a spike in the diffuse attenuation coefficient (Fig. 8C). The bloom event in June led to much higher levels of $P_{H, T}$ at Stn 5.2 than any at Stn 4.3 that year, while the washout event in August led to a much lower value (Fig. 8D). The results of many such events can be seen in Fig. 2, with the main effect being an up-estuary reduction in $P_{H, T}$ due to episodic washout of biomass and increased turbidity predominating over the occasional localized blooms. While such events occur throughout the year, Fig. 7 indicates that the reductions predominate in spring and fall.

\section{Components of the variance}

Analysis of the variance components in Eq. (9b) showed that $\operatorname{var}(A)$, the scale factor, was by far the 

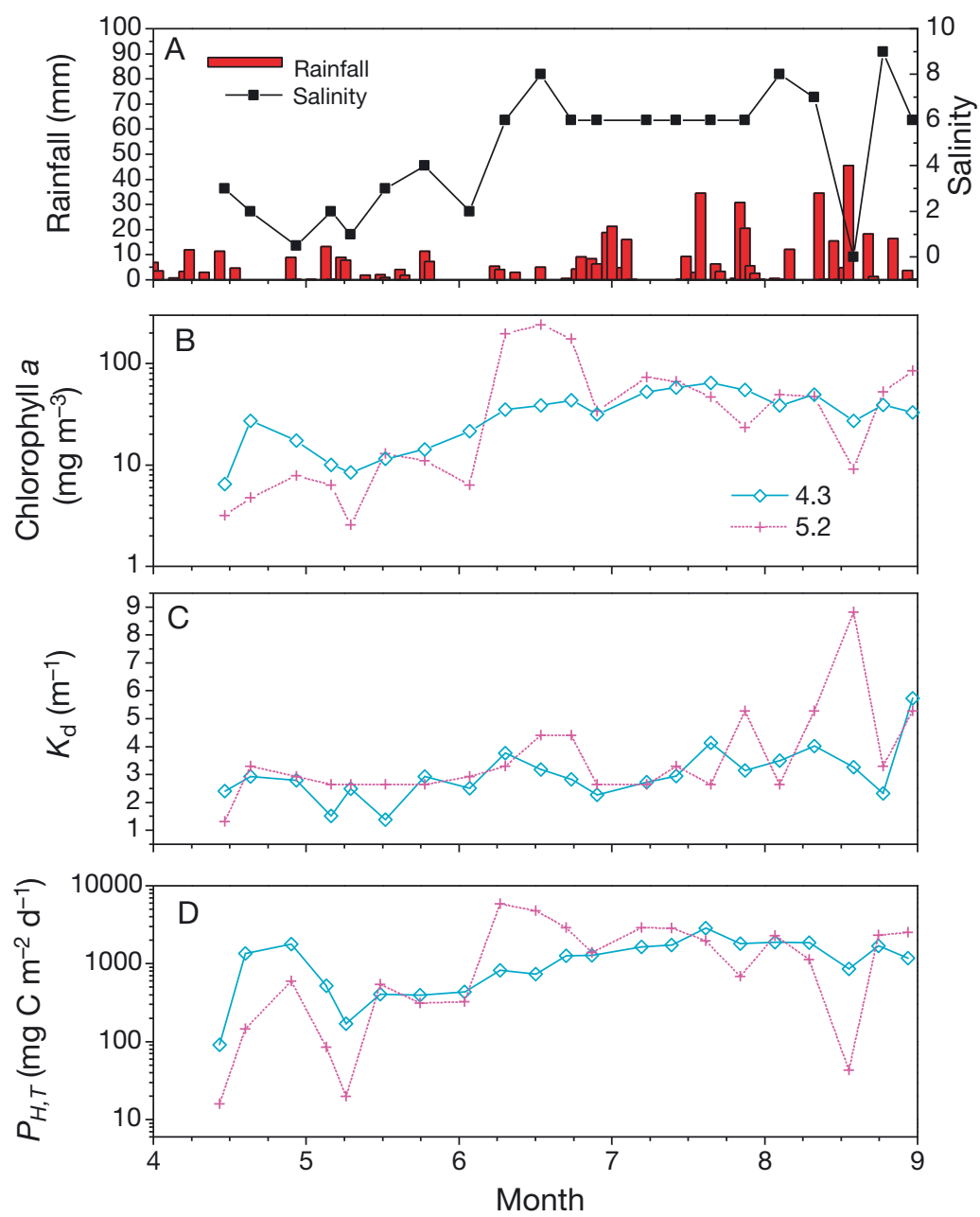

Fig. 8. Temporal variation of factors affecting daily production during spring and summer at Stns 4.3 and 5.2 for the year 1994. (A) Rainfall and salinity; (B) phytoplankton chlorophyll concentration; (C) diffuse attenuation coefficient, $K_{\mathrm{d}}(\mathrm{D})$ daily production, $P_{H, T}$. Symbols for stations are identified in panel B

dominant contributor to var $\left(P_{H, T}\right)$ (Fig. 9A). $\operatorname{Var}\left(F_{0, H}\right)$ was next largest in magnitude, while all of the covariance terms and the spectral correction factor, $\operatorname{var}\left[S\left(Z_{\mathrm{OD}}\right)\right]$, were small. Thus, while the spectral correction itself was sizeable and important to make to calculate the correct magnitude of $P_{H, T}$ variability in the correction factor was a minor source of variance in $P_{H, T}$. For comparison, the variance of the residuals of the GLM with interactions (Eq. 11) is shown as the red line through the variance for $\ln \left(P_{H, T}\right)$ in Fig. 9A. About $49 \%$ of the variance in $\ln \left(P_{H, T}\right)$ is associated with factors other than seasonal, interannual, and spatial variability.

Positive contributions to $\operatorname{Var}(A)$ were dominated nearly equally by $\operatorname{var}(B)$ and $\operatorname{var}\left(P_{\max }^{B}\right)$, followed by $\operatorname{var}\left(K_{\mathrm{d}}\right)$ (Fig. 9B, solid bars), but covariance terms made important positive and negative contributions.
The covariance between $K_{\mathrm{d}}$ and $B$ (multiplied by 2 in Fig. 9B to gauge the magnitude of its effect) was the third largest in magnitude, and its effect was negative (i.e. dampens variance) due to the occurrence of $K_{\mathrm{d}}$ in the denominator of the expression defining $A$, and the positive covariance between them (Eq. 10b). The next 2 covariance terms ranked $\left|\operatorname{cov}\left(P_{\text {max }}^{B} K_{\mathrm{d}}\right)\right|>\operatorname{cov}\left(B_{1} P_{\text {max }}^{B}\right)$ with the former negative and the latter positive (Fig. 9B). All of the terms involving photoperiod, $D$, omitted from Fig. 9B, were minor contributors to $\operatorname{var}(A)$.

The foregoing GLM analysis of factors governing the relative magnitude of $P_{H, T}$ (and $A$ in particular) indicated that $B$, $P_{\text {max }}^{B}$ and $K_{\mathrm{d}}$ all had similar seasonal patterns with winter minima and summer maxima (Fig. 4B). This seasonality, which may be driven by different, covarying factors (e.g. light via $E_{0}{ }^{\mathrm{m}}$ and $D$, Fig. 4B, and temperature effects on $P_{\max }^{B}$ Gallegos 2012a) may dominate the covariance terms and obscure other modes of covariance. A similar analysis was, therefore, conducted on residuals of a seasonal GLM with Month as the only factor to remove the seasonality. Removal of the seasonal pattern altered the relative importance of certain terms and covariances comprising var(A) (Fig. 9B, hatched bars). As expected, the overall variance in $A$ was reduced by removal of the seasonal trend, while $\operatorname{var}(B)$ contributed relatively more and $\operatorname{var}\left(P_{\max }^{B}\right)$ slightly less to $\operatorname{var}(A)$ than in the original series (Fig. 9B, hatched bars). Interestingly, the covariance between $P_{\max }^{B}$ and $B$ changed signs, and that between $P_{\max }^{B}$ and $K_{\mathrm{d}}$ became insignificant, while the covariance between $B$ and $K_{\mathrm{d}}$ maintained about the same proportion of $\operatorname{var}(A)$ as in the original series (Fig. 9B).

\section{DISCUSSION}

\section{Analysis of primary production}

Use of Eq. (7) for calculation of primary production is convenient and appropriate for the Rhode River because the system is generally well mixed, and biomass was measured on depth-integrated water samples, averaging over any subsurface biomass peaks 


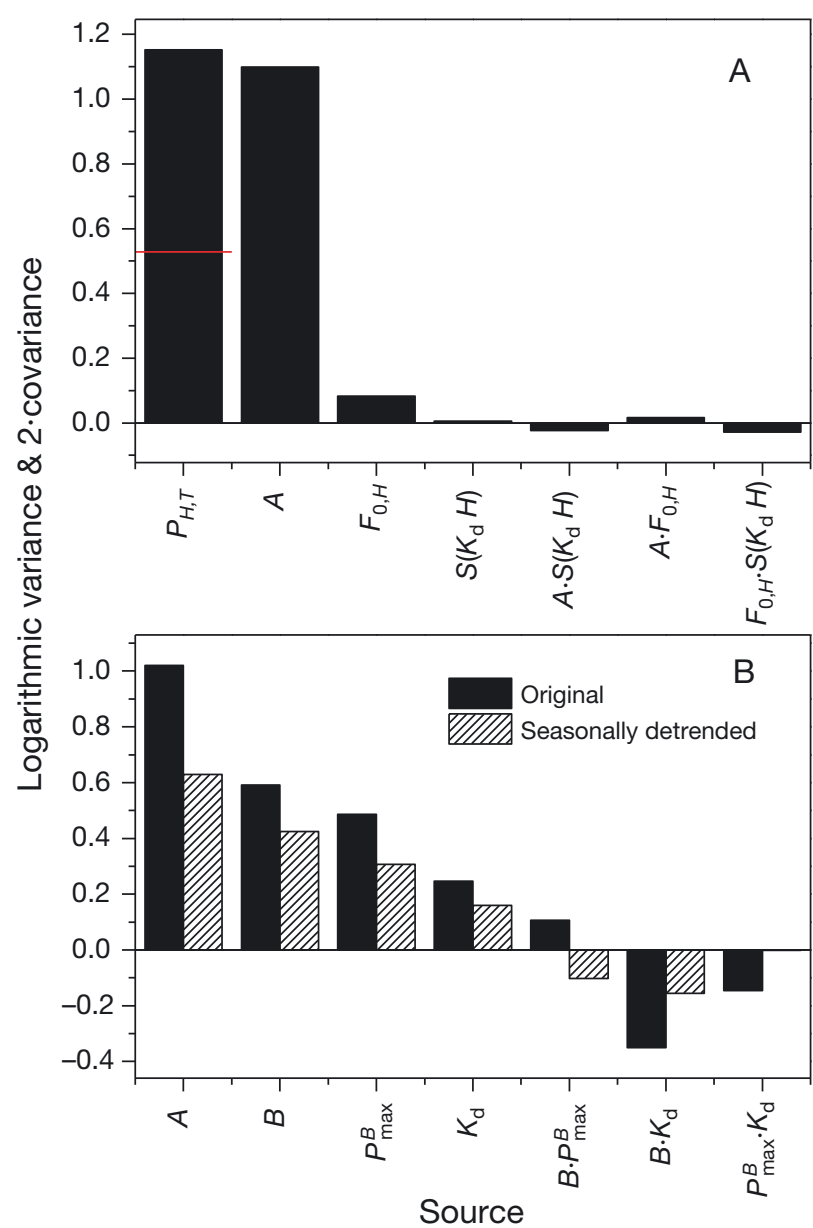

Fig. 9. (A) Variance of natural-log transformed daily production, $P_{H, T}$, and the terms comprising it (Eq. 9b): the scale factor $A_{i}$ the dimensionless depth-integral, $F_{0, H}\left(E_{*}^{\mathrm{m}}\right)$; the spectral correction factor, $S\left(Z_{\mathrm{OD}}\right)$; and $2 \times$ the covariances. Red line through bar $P_{H, T}$ is the variance of the residuals of the GLM, Eq. (11). (B) as in (A) for natural-log transformed scale factor, $A$, and the terms comprising it (Eq. 10b): Solid bars, original data; hatched bars, residuals of the GLM with Month as the only factor to remove seasonal patterns in the data. Logarithmic designations omitted from axis labels for clarity

that occasionally may have been present. The formalism of Platt \& Sathyendranath (1993), as logtransformed and analyzed here (Eqs. 9 \& 10), provides a powerful and objective way of analyzing and ranking the relative importance of the different factors controlling the relative magnitude and variance of primary productivity. Log-transformation has been used previously to analyze primary production data, but primarily as a normalizing transformation to condition the data for regression analysis (Boyer et al. 1993, Harding et al. 2002). Since Eq. (7) is exact and multiplicative, log-transformation permits additive accounting of the contributions by the causal factors on seasonal (Fig. 4A) and spatial (Fig. 5A) scales. It is important to remember that log-transformation means that the analysis is performed in terms of percent variations. Thus, a fixed percentage change in any one of the terms $B, P_{\max }^{B} D$, or $K_{\mathrm{d}}$ results in the same percentage change in $A$ and $P_{H, T}$. The relative importance of these factors in controlling the percent variability in $P_{H, T}$ in any particular region, therefore, depends on the relative (percent) variability in the governing terms in the data being considered. For example, Marañón \& Holligan (1999) found a greater contribution of $P_{\max }^{B}$ to variability in primary production compared with $B$ along meridional transects in the Atlantic. Here, the relative contributions of $B$ and $P_{\max }^{B}$ were nearly equal, although removal of the common seasonality between $B$ and $P_{\max }^{B}$ increased the relative importance of $B$ (Fig. 9B). Behrenfeld \& Falkowski (1997) argued that the contribution by the variance in $B$ would greatly exceed that due to $P_{\max }^{B}$ for the global ocean, on consideration that at the global scale, $B$ varies over 3 orders of magnitude (OM) compared with about 2 OM for $P_{\max }^{B}$.

Covariances between terms, for example between $B$ and $P_{\max }^{B}$ or between $B$ and $K_{\mathrm{d}}$, do not affect the validity of Eqs. (9a) \& (10a) for the relative magnitudes of $\ln \left(P_{H, T}\right)$ and $\ln (A)$. That is because the effect of any percentage increase in $K_{\mathrm{d}}$ entailed by a percentage increase in $B$ is fully captured in the sum, and similarly for any covariance between $B$ and $P_{\text {max }}^{B}$. Such covariances do, however, either augment or dampen the variance of $P_{H, T}$ and $A$ depending on the sign of the covariance. The effects of these covariances are specified by the $\pm 2 \operatorname{cov}[\bullet, \bullet]$ terms in Eqs. (9b) \& $(10 \mathrm{~b})$. Interestingly, the effect of the $2 \mathrm{cov}\left[\ln (B), \ln \left(K_{\mathrm{d}}\right)\right]$ term was, in fact, the third ranking component in the $\operatorname{var}[\ln (A)]$, and removal of seasonal trends did not alter that relationship (Fig. 9B). The damping of the variance in $P_{H, T}$ by the covariance between $B$ and $K_{\mathrm{d}}$ is expected because light absorption and scattering by phytoplankton pigment contribute to light attenuation. A minimum scale for this factor appropriate for oceanic waters may be determined by consideration of a Case 1 (optical properties determined by phytoplankton and associated byproducts) optical model for $K_{\mathrm{d}}$. Neglecting the contribution to $K_{\mathrm{d}}$ by pure water, we may write (Morel 1988):

$$
K_{\mathrm{d}} \approx \chi^{\gamma}
$$

which upon log transformation becomes:

$$
\ln \left(K_{\mathrm{d}}\right) \approx \ln (\chi)+\gamma \ln (B)
$$

where $\chi$ and $\gamma$ are empirical coefficients. Since $\gamma$ 
becomes a slope upon log-transformation, then from the definition of the slope we may write:

$$
\operatorname{cov}\left[\ln (B), \ln \left(K_{\mathrm{d}}\right)\right] \approx \gamma \operatorname{var}[\ln (B)]
$$

Morel (1988) determined $\gamma=0.428$ for PAR in Case 1 waters, which when multiplied by 2 (Eq. 10b) would indicate that the damping effect of the covariance term could be just slightly less (i.e. $0.856 \times$ ) than the positive contribution of the $\ln (B)$ term itself. In the $20 \mathrm{yr}$ of $P_{H, T}$ examined here (Fig. 9B), $2 \operatorname{cov}\left[\ln (B), \ln \left(K_{\mathrm{d}}\right)\right]$ was about $0.59 \operatorname{var}[\ln (B)]$ in the unmodified data, and $0.37 \operatorname{var}[\ln (B)]$ in the seasonally de-trended data (Fig. 9B). A smaller proportionality is understandable for Case 2 waters, where we would expect Eq. (12a) to provide a poorer representation of $K_{\mathrm{d}}$ than in Case 1 waters. The weaker magnitude of the covariance term in seasonally de-trended data is expected in this system because the contributions to light attenuation by both the organic and inorganic particulate matter peak in late summer (Gallegos et al. 2005), and removal of both contributions to seasonality would further reduce the proportionality. Finally, the covariance between $B$ and $K_{\mathrm{d}}$ in advective regimes such as the upper estuary may turn negative when high flow increases turbidity while simultaneously reducing $B$ by washout (Fig. 8), thereby augmenting the variance in $P_{H, T}$. The magnitude and sign of the covariance terms are, therefore, highly diagnostic of processes governing the variance in $P_{H, T}$ at a wide range of scales, and this general approach should find application in a wide range of systems.

\section{Seasonal variability}

The position of the Rhode River as a sub-estuary in the mesohaline zone of the Chesapeake Bay means that it is influenced by a local watershed at its head and a remote, larger watershed at its mouth (Gallegos et al. 1992). This position has ramifications for both the seasonal and spatial dynamics of primary production. The mean seasonal variability of production in the Rhode River is similar to that in the main stem of the Chesapeake Bay, both systems having a late winter minimum and a late summer maximum (cf. Fig. 3A, Fig. 8 in Malone et al. 1988, see also Fig. 3 in Harding et al. 2002). This similarity in overall seasonality is, however, achieved by different dynamics of the causal factors. In the Chesapeake Bay, seasonal nutrient input and phytoplankton biomass are in phase and biomass peaks with the spring diatom bloom, while productivity is in phase with light and temperature and peaks in summer (Malone et al. 1988). Here, the main allochthonous $\mathrm{N}$ input to the lower estuary is at the mouth from the Chesapeake Bay in spring (Jordan et al. 1991a), but spring blooms may be suppressed by either exceptionally high flows which cause washout and high turbidity, or by low flows which fail to supply sufficient nitrogen (Gallegos et al. 1997, 2010). Unlike Chesapeake Bay however, the average seasonal chlorophyll biomass in the Rhode River peaked in summer rather than spring, so that the effects of both the biomass and photosynthetic capacity were strongly correlated and nearly in phase with one another (Fig. 4B) at seasonal time scales. The analysis of seasonal patterns here smooths over much interannual variability, particularly regarding the presence or absence of extraordinary spring blooms of the dinoflagellate Prorocentrum minimum (Gallegos et al. 1997). Such blooms, when present, shifted the peak chl a concentration to May, but they were too rare during this $20 \mathrm{yr}$ interval to cause more than a small local peak in the average biomass in May (Fig. 4B). The effect of these large blooms on deviations from the mean seasonal pattern of production and their contribution to interannual variation in annual production are analyzed elsewhere (Gallegos 2014).

Physiological processes also play a significant role in generating the mean seasonal progression of $P_{H, T}$. Dependence of $P_{\max }^{B}$ on temperature and dissolved inorganic carbon (Loftus et al. 1979, Falkowski \& Raven 2007) drive the winter minimum and summer maximum of that parameter (Gallegos 2012a); however, much short-term variability also occurs in $P_{\max }^{B}$ that is not well predicted by the available data, including species composition. Moreover, the low phytoplankton biomass and persistence of available dissolved inorganic nitrogen during winter (Jordan et al. 1991a) result from physiological limitation of phytoplankton growth by low temperature and incident light (Gallegos \& Jordan 1997). These physiological effects are, therefore, responsible for the observed covariation between $B$ and $P_{\max }^{B}$ on seasonal time scales which augmented the variance in log-transformed $A$ (Fig. 9B). Reduction of the contribution to the variance in $A$ of $P_{\max }^{B}$ relative to $B$ (Fig. 9B) in the seasonally detrended residuals indicates that, in this system, the seasonality of $P_{\max }^{B}$ is stronger than that of $B$. This could prove to be a useful metric for comparing the effects of different parameters on the relative magnitudes of event, seasonal, and interannual scales of variability in primary production across systems (Cloern \& Jassby $2008,2010)$. These observations underscore the 
complex interplay among biogeochemical, hydrological, and physiological factors in determining the seasonal variability of phytoplankton primary productivity.

In view of these complexities, it is not surprising that an extensive survey by Cloern \& Jassby (2008, 2010) of seasonal patterns in phytoplankton biomass in coastal systems worldwide revealed a wide range in seasonal amplitudes and peak months in phytoplankton biomass, with few generalities. Indeed, a recurring unimodal peak biomass in summer was by no means the dominant pattern, so that the seasonal pattern observed here is not expected to be typical of systems in which biomass is driven more by pulsed flow or the myriad of other factors affecting patterns of phytoplankton variability at the land-sea-sediment interface (Cloern \& Jassby 2008). These broader observations together with the potential for temporal separation of biomass and production peaks (Malone et al. 1988) mean that a continuum of seasonal patterns in daily production ranging from highly erratic to highly repetitive may be expected in coastal systems worldwide. A similar meta-analysis of the terms in Eq. $(10 a, b)$ would allow cross-system comparisons of the controls on the magnitude and variance of phytoplankton production.

\section{Spatial variability}

The position of the Rhode River as a mesohaline sub-estuary affected spatial patterns in phytoplankton production in several ways. The outermost station examined was $1.4 \mathrm{~km}$ beyond the mouth of the Rhode River, along the broad, open western shoulder of the Chesapeake Bay (Fig. 1) with minimal influence by the Rhode River (Loftus et al. 1972). The level of production at that station was maintained relatively constant at the next 3 stations up estuary (Figs. 3B \& 5B), despite a decrease in depth from 4 to $1.7 \mathrm{~m}$ (Jordan et al. 1991a). Analysis in terms of Eq. (10a) demonstrated that the relative constancy of $P_{H, T}$ over these first 4 stations was maintained by an up-estuary increase in chl a that was partially offset by increases in $K_{\mathrm{d}}$ (Fig. 5B). Some of this covariation between $B$ and $K_{\mathrm{d}}$ may be explained by the expected dependence explored above (Eq. 13). However, much of the spatial variability in $K_{\mathrm{d}}$ is governed by up-estuary increases in non-algal suspended solids and marsh-derived colored dissolved organic matter derived from increasing resuspension and proximity to terrestrial sources, respectively (Gallegos et al. 1990, 2005, Tzortziou et al. 2011).
At the next 2 stations further up-estuary, $P_{H, T}$ declined, initially due to bathymetry (Fig. 5A), then due to increased $K_{\mathrm{d}}$ (Fig. 5B). The decline in $F_{0, H}\left(E_{*}^{\mathrm{m}}\right)$ at Stns 3.8 and 4.3 was the main source of variability due to the dimensionless integral, suggesting that undue attention need not be given to determining its value, in particular, $E_{\mathrm{k}}$ (Behrenfeld \& Falkowski 1997). At the most upstream station, advective processes were seen to dominate the variability in $P_{H, T}$ (Fig. 8), with washout of biomass and elevated $K_{\mathrm{d}}$ predominating over occasional bloom stimulation to reduce mean production at that station (Fig. 7). Discharge from the local watershed is flashy year round (see, e.g. Fig. 5 in Gallegos et al. 2005). The pattern observed in the Month $\times$ Station interactive term at the uppermost station suggests an interaction between flow and seasonal factors affecting phytoplankton growth (light, photoperiod, temperature) resulting in stimulation of blooms in summer, and washout at other times, similar to observations in other coastal systems (Bouman et al. 2010).

\section{CONCLUSIONS}

The formalism of Platt \& Sathyendranath (1993) provides an effective framework for calculating and analyzing daily production in this shallow, eutrophic estuary. An empirical factor was derived to correct calculations based on PAR and downwelling irradiance for spectral selectivity of phytoplankton absorption of spectral scalar irradiance. On average, use of PAR and downwelling irradiance led to a $28 \%$ overestimation of daily production, with some calculations up to $40 \%$ overestimated. Expression of the fractional correction as a function of optical depth corrected the estimates and preserved the multiplicative form of the equation, enabling log-transformation for linear analysis of seasonal and spatial patterns in factors controlling daily production.

The seasonal variation in daily production exceeded the spatial and interannual sources. Similar to the neighboring Chesapeake Bay, daily production in the Rhode River peaked in summer and was minimal in late winter, but the pattern of the causal factors differed. In the Rhode River, the seasonal averaged biomass peaked in summer, within 1 mo of the peak in photosynthetic capacity, unlike the Chesapeake Bay in which phytoplankton biomass peaks in spring.

The analysis demonstrated several patterns by which estuarine production is influenced by proximity to land. Spatially, there was a zone in which the 
shoaling bathymetry was offset by compensating longitudinal gradients in phytoplankton biomass and light attenuation, maintaining statistically constant production; there was a zone in which production was diminished due to shoaling of the bathymetry, such that the depth integral was incompletely expressed; and there was a zone in which freshwater flow caused lower mean but higher variability in production by either inducing large, local blooms, or more frequently by advective washout of biomass and elevation of turbidity. In the advective region, the decrease in production was accompanied by compression of the seasonal signal, due to predominance of washout events in spring and fall. The analytical approach adopted here allowed these patterns to be discerned against a high degree of overall variability, and should be similarly useful in a wide range of systems.

Acknowledgements. I thank S. Hedrick for measurements of ${ }^{14} \mathrm{C}$ uptake, and N. Kobayashi, A. M. Hartsig, K. Jarriel, and S. Benson for assistance in the field, and P. Neale for discussions of the work. Funding was provided by the Smithsonian Environmental Sciences Program and Federal funds of the Smithsonian Institution. Funds for measurement of inherent optical properties were provided by the Coastal Intensive Site Network (CISNet) program of the United States Environmental Protection Agency (USEPA) through grant R826943-01-0. Comments by 3 anonymous reviewers improved the manuscript.

\section{LITERATURE CITED}

Arfi R, Guiral D, Bouvy M (1993) Wind induced resuspension in a shallow tropical lagoon. Estuar Coast Shelf Sci 36:587-604

> Armstrong RA (2006) Optimality-based modeling of nitrogen allocation and photoacclimation in photosynthesis. Deep-Sea Res II 53:513-531

Behrenfeld MJ, Falkowski PG (1997) A consumer's guide to phytoplankton primary productivity models. Limnol Oceanogr 42:1479-1491

Bouman H, Platt T, Sathyendranath S, Stuart V (2005) Dependence of light-saturated photosynthesis on temperature and community structure. Deep-Sea Res I 52: 1284-1299

Bouman HA, Nakane T, Oka K, Nakata K, Kurita K, Sathyendranath S, Platt T (2010) Environmental controls on phytoplankton production in coastal ecosystems: a case study from Tokyo Bay. Estuar Coast Shelf Sci 87:63-72

> Boyer JN, Christian RR, Stanley DW (1993) Patterns of phytoplankton primary productivity in the Neuse River estuary, North Carolina, USA. Mar Ecol Prog Ser 97: 287-297

- Brush MJ, Brawley JW (2009) Adapting the light-biomass (BZI) models of phytoplankton primary production to shallow marine ecosystems. J Mar Syst 75:227-235

> Bubenheim DL, Bugbee B, Salisbury FB (1988) Radiation in controlled environments: influence of lamp type and filter material. J Am Soc Hortic Sci 113:468-474
Cloern JE, Jassby AD (2008) Complex seasonal patterns of primary producers at the land-sea interface. Ecol Lett 11: 1294-1303

> Cloern JE, Jassby AD (2010) Patterns and scales of phytoplankton variability in estuarine-coastal ecosystems. Estuar Coast 33:230-241

Falkowski PG, Raven JA (2007) Aquatic photosynthesis. Princeton University Press, Princeton, NJ

> Gallegos CL (2012a) Phytoplankton photosynthetic capacity in a shallow estuary: environmental correlates and interannual variation. Mar Ecol Prog Ser 463:23-37

Gallegos CL (2012b) Photosynthetic parameters, chlorophyll concentration, and diffuse attenuation coefficients in the Rhode River, Maryland (USA), 1990-2009. PANGAEA, Data Publisher for Earth \& Environmental Science, doi: 10.1594/PANGAEA.816494

Gallegos CL (2013) Phytoplankton daily production in the Rhode River, Maryland (USA), 1990-2009. PANGAEA: Data Publishers for Earth \& Environmental Science, doi: 10.1594/PANGAEA. 819825

Gallegos CL (2014) Long-term variations in primary production in a eutrophic sub-estuary. II. Interannual variations and modeling. Mar Ecol Prog Ser 502:69-83

Gallegos CL, Jordan TE (1997) Seasonal progression of factors limiting phytoplankton pigment biomass in the Rhode River estuary, Maryland (USA). I. Controls on phytoplankton growth. Mar Ecol Prog Ser 161:185-198

> Gallegos CL, Correll DL, Pierce JW (1990) Modeling spectral diffuse attenuation, absorption, and scattering co-efficients in a turbid estuary. Limnol Oceanogr 35: 1486-1502

> Gallegos CL, Jordan TE, Correll DL (1992) Event-scale response of phytoplankton to watershed inputs in a subestuary: timing, magnitude, and location of phytoplankton blooms. Limnol Oceanogr 37:813-828

- Gallegos CL, Jordan TE, Correll DL (1997) Interannual variability in spring bloom timing and magnitude in the Rhode River, Maryland USA: observations and modeling. Mar Ecol Prog Ser 154:27-40

> Gallegos CL, Jordan TE, Hines AH, Weller DE (2005) Temporal variability of optical properties in a shallow, eutrophic estuary: seasonal and interannual variability. Estuar Coast Shelf Sci 64:156-170

Gallegos CL, Jordan TE, Hedrick SS (2010) Long-term dynamics of phytoplankton in the Rhode River, Maryland (USA). Estuar Coast 33:471-484

> Gallegos CL, Werdell PJ, McClain CR (2011) Long-term changes in light scattering in Chesapeake Bay inferred from Secchi depth, light attenuation, and remote sensing measurements. J Geophys Res 116, C00H08, doi:10. 1029/2011JC007160

Geider R, MacIntyre HL (2002) Physiology and biochemistry of photosynthesis and algal carbon acquisition. In: Williams PJleB, Thomas DN, Reynolds CS (eds) Phytoplankton productivity: carbon assimilation in marine and freshwater ecosystems. Blackwell, Oxford

Geider RJ, MacIntyre HL, Kana TM (1998) A dynamic regulatory model of phytoplankton acclimation to light, nutrients and temperature. Limnol Oceanogr 43:679-694

> Gregg WW, Carder KL (1990) A simple spectral solar irradiance model for cloudless maritime atmospheres. Limnol Oceanogr 35:1657-1675

> Harding LW Jr, Mallonee ME, Perry ES (2002) Toward a predictive understanding of primary productivity in a temperate, partially stratified estuary. Estuar Coast Shelf 
Sci 55:437-463

Harrison WG, Platt T (1980) Variations in assimilation number of coastal marine phytoplankton: effects of environmental co-variates. J Plankton Res 2:249-260

> Hayes JP, Shonkwiler JS (2006) Allometry, antilog transformations, and the perils of prediction on the original scale. Physiol Biochem Zool 79:665-674

Jassby AD, Platt T (1976) Mathematical formulation of the relationship between photosynthesis and light for phytoplankton. Limnol Oceanogr 21:540-547

Jordan TE, Correll DL, Miklas J, Weller DE (1991a) Nutrients and chlorophyll at the interface of a watershed and an estuary. Limnol Oceanogr 36:251-267

> Jordan TE, Correll DL, Miklas J, Weller DE (1991b) Longterm trends in estuarine nutrients and chlorophyll, and short-term effects of variation in watershed discharge. Mar Ecol Prog Ser 75:121-132

Lawson SE, Wiberg PL, McGlathery KJ, Fugate DC (2007) Wind-driven sediment suspension controls light availability in a shallow coastal lagoon. Estuar Coast 30: 102-112

- Lewis MR, Smith JC (1983) A small volume, short-incubation-time method for measurement of photosynthesis as a function of incident irradiance. Mar Ecol Prog Ser 13: 99-102

Limpert E, Stahel WA, Abbt M (2001) Log-normal distributions across the sciences: keys and clues. BioScience 51: 341-352

Loftus ME, Subba Rao DV, Seliger HH (1972) Growth and dissipation of phytoplankton in Chesapeake Bay. I. Response to a large pulse of rainfall. Chesap Sci 13: 282-299

Loftus ME, Place AR, Seliger HH (1979) Inorganic carbon requirements of natural populations and laboratory cultures of some Chesapeake Bay phytoplankton. Estuaries 2:236-248

MacIntyre HL, Geider RJ, Miller DC (1996) Microphytobenthos: the ecological role of the 'Secret Garden' of unvegetated, shallow-water marine habitats. I. Distribution, abundance and primary production. Estuaries 19:186-201

Malone TC, Crocker LH, Pike SE, Wendler BW (1988) Influences of river flow on the dynamics of phytoplankton production in a partially stratified estuary. Mar Ecol Prog Ser 48:235-249

Marañón E, Holligan PM (1999) Photosynthetic parameters of phytoplankton from $50^{\circ} \mathrm{N}$ to $50^{\circ} \mathrm{S}$ in the Atlantic Ocean. Mar Ecol Prog Ser 176:191-203

Marañón E, Behrenfeld MJ, González N, Mouriño B, Zubkov MV (2003) High variability of primary production in oligotrophic waters of the Atlantic Ocean: uncoupling from phytoplankton biomass and size structure. Mar Ecol

Editorial responsibility: Graham Savidge,

Portaferry, UK
Prog Ser 257:1-11

Mobley CD (1994) Light and water. Radiative transfer in natural waters. Academic Press, New York, NY

Morel A (1988) Optical modeling of the upper ocean in relation to its biogenous matter content (case I waters). J Geophys Res 93:10749-10768

Nixon SW (1995) Coastal marine eutrophication: a definition, social causes, and future concerns. Ophelia 41: 199-219

> Nixon SW (2009) Eutrophication and the macroscope. Hydrobiologia 629:5-19

> Oviatt C, Keller A, Reed L (2002) Annual primary production in Narragansett Bay with no bay-wide winter - spring phytoplankton bloom. Estuar Coast Shelf Sci 54: 1013-1026

Peierls B, Hall N, Paerl H (2012) Non-monotonic responses of phytoplankton biomass accumulation to hydrologic variability: a comparison of 2 coastal plain North Carolina estuaries. Estuar Coast 35:1376-1392

> Platt T, Sathyendranath S (1988) Oceanic primary production: estimation by remote sensing at local and regional scales. Science 241:1613-1620

Platt T, Sathyendranath S (1993) Estimators of primary production for interpretation of remotely sensed data on ocean color. J Geophys Res 98:14561-14576

Platt T, Sathyendranath S, Ravindran P (1990) Primary production by phytoplankton: analytic solutions for daily rates per unit area of water surface. Proc Biol Sci 241: 101-111

Quinlan EL, Phlips EJ (2007) Phytoplankton assemblages across the marine to low-salinity transition zone in a blackwater dominated estuary. J Plankton Res 29: 401-416

Spatharis S, Tsirtsis G, Danielidis DB, Chi TD, Mouillot D (2007) Effects of pulsed nutrient inputs on phytoplankton assemblage structure and blooms in an enclosed coastal area. Estuar Coast Shelf Sci 73:807-815

> Tzortziou M, Neale PJ, Megonigal JP, Pow CL, Butterworth M (2011) Spatial gradients in dissolved carbon due to tidal marsh outwelling into a Chesapeake Bay estuary. Mar Ecol Prog Ser 426:41-56

UN Atlas of the Oceans (2013) www.oceansatlas.org/ servlet/CDSServlet?status=ND0xODc3JjY9ZW4mMzM9 KiYzNz1rb3M

> Ware DM, Thomson RE (2005) Bottom-up ecosystem trophic dynamics determine fish production in the Northeast Pacific. Science 308:1280-1284

> Yoshiyama K, Sharp JH (2006) Phytoplankton response to nutrient enrichment in an urbanized estuary: apparent inhibition of primary production by overeutrophication. Limnol Oceanogr 51:424-434

Submitted: April 30, 2013; Accepted: December 31, 2013 Proofs received from author(s): March 19, 2014 